\title{
Carbide tool wear mechanism in turning of Inconel 718 superalloy
}

\author{
Y.S. Liao, R.H. Shiue \\ Department of Mechnical Engineering, National Tawan University, Talpei, Taiwan
}

Received 3 August 1994; accepted 21 March 1995

\begin{abstract}
Wear surfaces of the culting tools are analyzed to study the wear mechanism of cemented carbide tools in turning of Inconel 718 superalloys. SEM and EPMA analyses indicated that the wear of carbide tools during bigh speed turning condition $\left(V-35 \mathrm{~m} \mathrm{~min}^{-1}\right)$ was caused by diffusion of elements ( $\mathrm{Ni}$ or $\mathrm{Fe}$ ) in workpiece into sool's binder $(\mathrm{Co})$ by a grain boundary diffusion mechanism. This action weakened the bonding strength between carbide particles (WC, TC, TaC) and the binder (Co). The carbide particles were then detached out of the cemented carbide tool by high flow siresses. The proposed grain boundary diffusion mechanism is also confirmed by theoretical analysis.
\end{abstract}

Keywords: Tool wcar mechanism; Carbides; Superalloys; Grain boundary diffusion

\section{Introduction}

Inconel 718 is one kind of nickel-iron base superalloys. Owing to its superior high temperature mechanical properties such as resistance to oxidation and corrosion, high tensile stress and rupture stress, etc., it has been widely applied for the parts in aerospace industry and nuclear reactor. But, the combined effects of poor thermal properties, high temperature strength, tendency to severe work handening, and high tool-workpjece affinity make machining of Inconel 718 very difficult because these properties result in high temperature, stress, and a thick adhering layer at the too]-work interface during machining [1].

The researches conducted so far for the machining of Inconel 718 are mainly focused on machining characteristics [ 2 41, and the appropriate tool material, geometry, and cutting conditions for economic machining $[5,6]$. Comparatively, very few have been done to identify tool wear mechanism during the machining of Inconel 718. Even though there are several studies on the machining of nickel base alloys by ceramics in recent years $[7,8]$, carbide tools remained to be the main tool materials in machining this kind of materiak owing to their high toughness and low cost. Ham had conducted a series of outting tests of Inconel 718 by $\mathrm{C} 2$ grade cartide [6], and he found that localized groove wear on side flank and chipping on the side cutting edge are the dominant causes of tool failure in some cases. But, in most cases, the tool wears uniformly and the flank wear progresses uniformly a: : ilting time increases up to the point where the tool fails. Based on the fractography of the tool surface after service,
Focke et al, had concluded that abrasion wear plays the most important role on the wear of cutring tools in turning of Inconel 718 [9]. The groove wear on minor tlank of cemented carbide tool in turning of pure nickel had been studied by Tan [10]. He found that temperature is the main driving force to cause tool wear. His proposal for tool wear mechanism is not different from carbide tool wear in machining of mild steels. Kramer and Suh proposed the solution wear theory which attributed the wear of carbide tool to the solubility of tool particles in material [ 11 ]. By observing the chip flow pattern, Wright and Chow concluded that the collapse of cutting edge in machining of nickel base alloys is mainly due to the increase of normal stress acting on the cutting edge [12]. Al] the studies stated above certainly contributed to the understanding of the failure of carbide tools in the machining of nickel base alloys. However, the investigations are not comprehensive. The proposal of Tan $[10]$ is not quite true as the flow stress in machining Inconel 718 is high, and it is expected that this high stress would contribute to wear of the cutting tool. The study hy Kramer and Suh [11] required more evidences to support their work as it is purely based on theoretical analysis. The "macro" approach of Wright and Chow [12] overlooked some pertinent information, besides, since the temperature in cutting of Inconel 718 is very high, other wear mechanisms besides abrasion wear are expected.

In this paper, the wear surfaces of cutting tools are investigated in detail using "micro" analysis, more evidences are given, and a new carbide tool wear mechanism in cutting of Inconel 718 is proposed. 


\section{Experiment}

The experiments are carried out on a $7.5 \mathrm{hp}$ engine lathe under semi-orthogonal, and dry culting condi ion. The work material is Inconel 718 superalloy in either solid solution or aged state. Its chemical compositions are given in Table 1. The feed $f$ and depth of cut $d$ are $0.101 \mathrm{~mm} \mathrm{rev}^{-1}$ and $1.5 \mathrm{~mm}$, respectively, and they are not varied throughout the experiments. The cutting speed $V$ is either $35 \mathrm{~m} \mathrm{~min}^{-1}$ (high speed) or $15 \mathrm{~m} \mathrm{~min}^{-1}$ (low speed). The total cutting time is $3 \mathrm{~min}$. The tool materials are $\mathrm{K} 20$ and P20 carbides. respectively with the geometry of $0^{\circ}$ inclination angle, $6^{\circ}$ side rake angle. $0^{\circ}$ approach angle, and $0.4 \mathrm{~mm}$ nose radius. The chemical compositions of tool materials are also given in Table 1. The cutting forces (principle force $F_{p}$, feed force $F_{4}$, and radial force $F_{\mathrm{r}}$ ) are measured by the Kistler dynamometer. Since the turning process in the experiment can be considered as a plane strain and steady state condition, the radial force is neglected.

\section{Results}

The measured results for turning of aged Inconel 718 are summarized in Fable 2. In the table, $t_{\mathrm{c}}$ is the chip thickness, $a$ is the chip-tool contact length, VB and CR are flank wear length and crater wear depth. By incorporating these results with cutting mechanies [1], the average stresses in the primary and seconday deformation zones can be computed. The temperaturs in each deformation zone can then be estimated by using the moving heat source theory [1]. Mathematical expressions used to compute stresses and temperatures are summarized in Appendix $A$, and the computed results are given in Table 3 . In the table, $S_{\mathrm{s}}$ and $S_{\mathrm{n}}$ denote shear and normal stresses, $\mu$ is the coefficient of friction. $T_{s}$

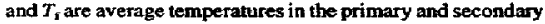
deformation zones. From these tables, it is found that the flow stress $(1.5-2.5 \mathrm{GPa})$ and temperalure $\left(800-1200^{\circ} \mathrm{C}\right)$ in cutting of $\ln 718$ are very high, and they are atuributed to serious work hardening of In718 during turning.

The wear surface of the chip-10ol interface of the K-type carbide tool is shown in Fig. 1. A sticking layer can be clearly seen. The sticking region which is very close to the cutting efge shows dimple-like ductile fractures (this particular region has the highest temperature, and is called seizure region). This phenomenon is quite different from that when mild steel is machined where the seizure region is smaller, and it is located at around (1/2)a distance from the cutting edge (note: $a$ is the chip-toolcontact lengh). The occurrence of sticking region confirms the fact that high stresses and temperature are acting on the chip-tool interface. The same region has also been found in P-type carbide tool when it is used under the same turning conditions. When Inconel 718 is machined under a high speed cutting condition, it is also

Table 1

Chemical composition of wotk and tool materials

\begin{tabular}{|c|c|}
\hline Materials & Specifications \\
\hline Inconel & $\begin{array}{l}50-55 \% \mathrm{Ni}, 0.08 \% \mathrm{C}, 0.35 \% \mathrm{Mn}, 18.5 \% \mathrm{Fe}, 0.015 \% \mathrm{~S}, 0.35 \% \mathrm{Si}, 0.3 \% \mathrm{Cu}, 19 \% \mathrm{Cr}, 3.05 \% \mathrm{Mo} .5 .3 \%(\mathrm{Nb}+\mathrm{Ta}), 0.9 \% \mathrm{~T}, 0.5 \% \mathrm{Al}, \\
0.95 \% \text { B }\end{array}$ \\
\hline $\begin{array}{l}\text { K20 carbide } \\
\text { P20 carbide }\end{array}$ & $\begin{array}{l}94 \% \text { WC, } 6 \% \text { Co } \\
66.2 \% \text { WC, } 10.8 \% \text { TaC, } 12.8 \% \text { TiC. } 10.2 \% \text { Co }\end{array}$ \\
\hline
\end{tabular}

Table 2

Measured results in machining of aged fnconel $7: 18$

\begin{tabular}{|c|c|c|c|c|c|c|c|c|}
\hline Tool material & $V\left(\mathrm{mmin}^{-1}\right)$ & $F_{p}(N)$ & $F_{4}(\mathrm{~N})$ & $t_{c}(\mathrm{~mm})$ & $a(\mathrm{~mm})$ & $V B\left(\mu \mathrm{min} \min ^{-1}\right)$ & $\mathrm{CR}\left(\mu \mathrm{m} \min ^{-1}\right)$ & $V_{B_{\max }}(\mu \mathrm{rm})$ \\
\hline \multirow[t]{2}{*}{ P2O } & 15 & 720 & 754 & 0.279 & 0.390 & 88.2 & 6.7 & 294 \\
\hline & 35 & 780 & 617 & 0.191 & 0.210 & 1340 & 16.2 & $\pi 7$ \\
\hline \multirow[t]{2}{*}{$\mathrm{k} 20$} & 15 & 672 & 466 & 0.238 & 0.335 & 53.3 & $<1.0$ & 160 \\
\hline & 35 & 715 & 504 & 0.273 & 0.365 & 55.7 & 10.7 & 167 \\
\hline
\end{tabular}

Table 3

Computed results in machining of aged tnconel 718

\begin{tabular}{|c|c|c|c|c|c|c|c|c|}
\hline \multirow[t]{2}{*}{ Tool material } & \multirow[t]{2}{*}{$V\left(\operatorname{mmin}^{-1}\right)$} & \multicolumn{2}{|l|}{ Primary } & \multicolumn{2}{|l|}{ Secondary } & \multirow[t]{2}{*}{ H } & \multirow[t]{2}{*}{$T_{3}\left({ }^{\circ} \mathrm{C}\right)$} & \multirow[t]{2}{*}{$T_{1}\left({ }^{\circ} \mathrm{C}\right)$} \\
\hline & & $S_{4}(\mathrm{GPa})$ & $S_{1}$ (GPa) & $S_{n}(\mathrm{GPa})$ & $S,(\mathrm{GPa})$ & & & \\
\hline \multirow[t]{2}{*}{$\mathbf{P 2 0}$} & 15 & 2.19 & 0.95 & 1.15 & 1.36 & 1.180 & 594 & 891 \\
\hline & 35 & 2.90 & 1.23 & 2.35 & 2.11 & 0.896 & 779 & 1337 \\
\hline \multirow[t]{2}{*}{$\mathrm{K} 20$} & is & 1.83 & 1.13 & 1.28 & 1.01 & 0.788 & 642 & 467 \\
\hline & 35 & 1.69 & 1.15 & 1.25 & 1.00 & 0.801 & 365 & 1047 \\
\hline
\end{tabular}




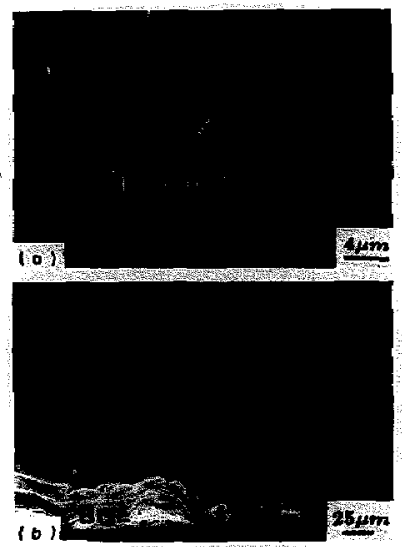

Fig. I. Ratce face of $K 20$ catbide: (a) wenr surface and (b) magaification of the area $A$ (aged In $718, V=35 \mathrm{~m} \mathrm{~min}^{-1}$; mutations C.E. and C.F.D. in the photograph stand for eutting edge and chip flow direction).

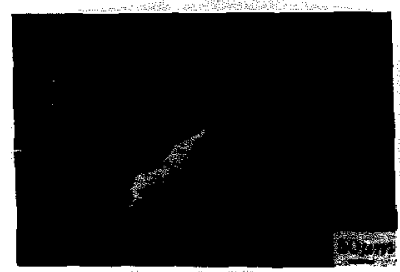

Fig. 2. Wear surface on the ralce face near the nose radius: A, chipping; $B$, BUE (aged In 718, K20 carbide, $V=35 \mathrm{~m} \mathrm{~min}^{-1}$ ),

very often that a built up edge (BUE) would form at the cutting edge. Fig. 2 shows a wear surface of the rake face near the nose radius. From the figure, BUE and chipping of the cutting edge can be clearly seen. The occurrence of BUE implies that there is high chemical affinity due to high temperature existent on the chip-tool interface besides high stresses.

A typical wear surface on the flank face of K-type carbide is shown in Fig. 3(a) and Fig. 3(b). Similar to rake face, there is a large amount of sticking layer. When P-type carbide is used, the sticking layer can also be found, but comparatively, the wear is more irtegular, the flank wear length is larger, and the groove is deeper. Inspecting the groove as that shown in Fig. 4(a) ind Fig. 4(b), it can be seen that tool particles are subjected to high stresses which cause loss of large amount of $\mathrm{Co}$ and the local detachment of WC or
(W,Ta,Ti)C from the base material. It is also noted that the flow stress could even be high enough to cause the fracture of tool particles (refer to that pointed by the arrow in Fig. 4(b) ).

In order to study the fractography of the carbide tools on the chip-tool interface, the rake face of the cutting tool is hot

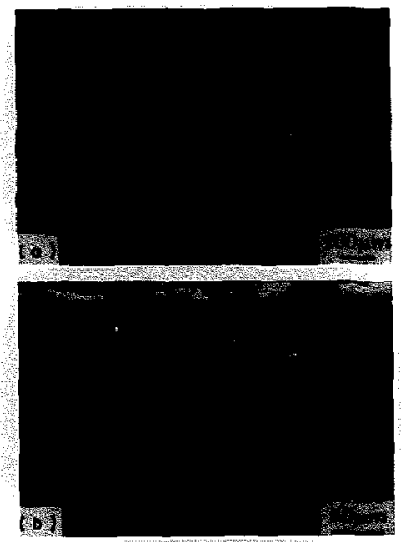

Fig. 3. Typical tank face: (a) wen surface and (b) magnification of the flank wear (solid sol. In 718, K20 carbide, $V=15 \mathrm{~m} \mathrm{~min}^{-1}$ ).

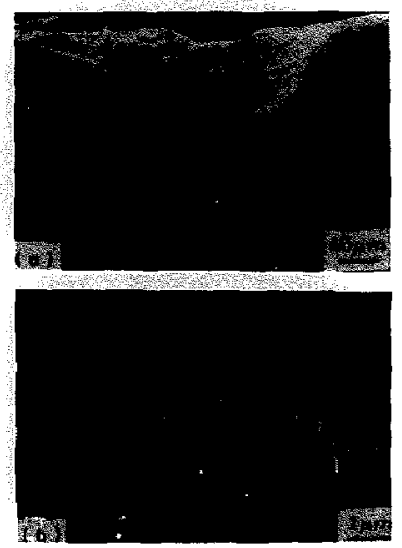

Fig 4. Groove wear and lis microstructure: (a) shape of the gronve and (b) magnification of the area $A$ (solid sol. In 718, P20 carbide, $V=35 \mathrm{~m}^{-1} \mathrm{in}^{-1}$ ). 

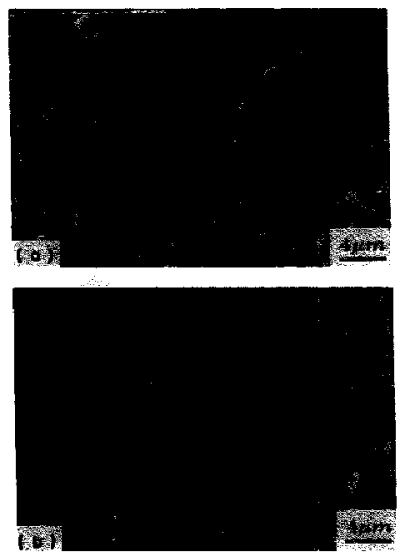

Fig. 5. Rake face of the new curting lools after hot etching: (a) P20 cabide and (b) K20 catide.

etched at $90^{\circ} \mathrm{C}$ for $1 \mathrm{~h}$ using the $40 \mathrm{ml}$ mathyl $+40 \mathrm{ml}$ $\mathrm{HCl}+2 \mathrm{~g} \mathrm{CuCl}_{2}$ etching fuid. The thick sticking layer on the tool surface can be removed by this process. The surfaces of new P-20 and K-20 carbide tools are shown in Fig. 5( a) and Fig. 5(b), and those after the tools have been serviced for $3 \mathrm{~min}$ using high speed cutting condition ( $V=35 \mathrm{~m} \mathrm{~min}^{-1}$ ) are shown in Fig. 6(a) and Fig. 6(b). It car be seen from these figures that a large number of tool particl as are detached from the tool surface for both P-type and K-type tools under high speed cutting conditions. Those 1001 particles remained on the surface are not distorted, broken, nor deformed.

When the particles on the tool surface before and after service are compared, it is noted that rounding of the particles takes place for both tools after service. There are two possible explanations for this result. Firstly, high flow stresses cause the originally multi-angles, irregular, and sharp tool particles to wear locally, and eventually the tool particles become rounded. If this conjecture is true, then all WC particles or (W,Ta,Ti)C particles should deform along a particulardirection (i.e. chip flow direction). But, when Fig. 6(a) and Fig, 6(b) are examined, it is found that the tool particles are randomly distributed with no specific orientations on the tool surface. In addition, tool particles inside the tool surface show rounding characteristics as well. Hence, there is very slight possibility that high flow stresses play the principle role on rounding of the particles. Secondly, since the etching fluid for Inconel 718 does not react with $\mathrm{WC}$ nor $(\mathrm{Ta}, \mathrm{Ti}, \mathrm{W}) \mathrm{C}$ of the tool particles, instead, it only reacts with the binder Co and Inconel 718 hase material. Hence, if there is small amount of work material diffused into the cutting tool, and if the positions occupied by $\mathrm{Co}$ and the intermetallic phase between Co and WC or (W,Ta.Ti)C are replaced by this work material, then when the Inconel 718 etching fuid is applied, Co itself and intermetallic phaze between Co and WC or ( $W, T a, T i) C$ would be etched away easily. This process will result in rounding of the tool particles. The above discussion also implies that diffusion and solubility phenomena had occurred between work and tool materials under high temperature conditions.

The line scan of EPMA is employed to analyze the concentration variations of $\mathrm{W}, \mathrm{Co}$ and $\mathrm{Ta}$ of tool clements and $\mathrm{Ni}$ and $\mathrm{Fe}$ of work elements beneath the rake face. It is found that there is no conspicuous change of tool elements $\mathrm{W}, \mathrm{Co}$ and Ta. But as shown in Fig. 7, there is evidence that work elements $\mathrm{Ni}$ and $\mathrm{Fe}$ had entered into the cutting tool. Fig. 8 shows similar result, but the evidence is less obvious due to a chip adherent to the tool face. Nevertheless, the more violent variation of the scanning line beneath the rake foce as compared with that of the base line (to the right of the chip in Fig. 8) can still be vaguely seen. Because the temperature in the experiment is very high (about $1000^{\circ} \mathrm{C}$ ), hence, it is believed that the work materials entered into the cutting tool by ways of diffusion. Based on line scan. the diffusion distance for $\mathrm{Ni}$ or $\mathrm{Fe}$ is estimated, and it is larger than around $10^{1} \mathrm{\mu m}$.

The quantitative analysis of the elements $\mathrm{Ni}$ and Fe beneath the rake face of the cutting tool by EPMA is shown in Fig. 9(a) and Fig. 9(b). From these figures it is realized that there are $\mathrm{Ni}$ and $\mathrm{Fe}$ at $>10^{1} \mathrm{~mm}$ below the rake face. The EPMA Mapping (Fig. 10) also provides the evidence that
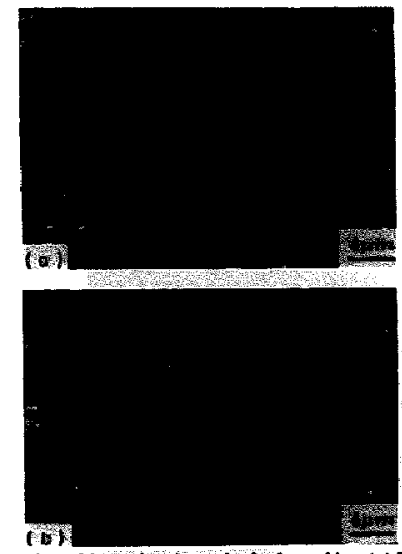

Fig. 6. Rake face of the wed cutting towls aner bot etching: (a) P20 carbide and (b) K20 carbide (23od ka $718, V=35$ w $\min ^{-1}$ ). 


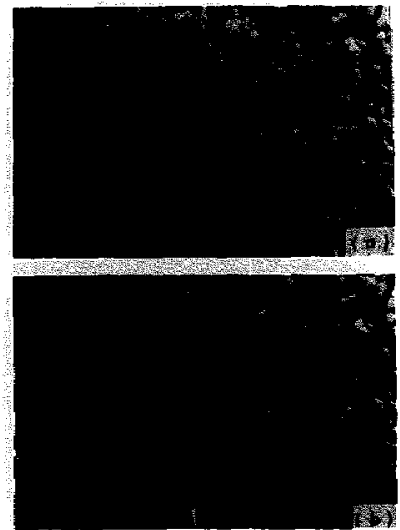

Fig. 7. EPMA line scan of work elements benesth the rake face of $P 20$ cerbide; (a) Ni and (b) Fe (aged In 7j8, $V=35 \mathrm{~m} \mathrm{~min}^{-1}$ ).
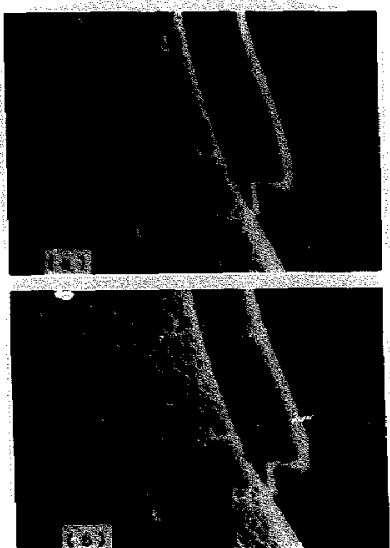

Fig. 8. EPMA line scan of work elements benewh the rake face of $\mathbf{k 2 0}$ carbide: (a) Ni and (b) Fe (aged In 718, V=35 $\mathrm{m} \mathrm{min}^{-1}$ ).

$\mathrm{Ni}$ and $\mathrm{Fe}$ are existent in the binder Co (Fig. 10(c), although the amount of $\mathrm{Ni}$ is small).

The back of the chip inspected by SEM is shown in Fig. 11 (a). As pointed by the arrow, the tool particles embedded in the chip can be seen. Its compositions are analyzed by
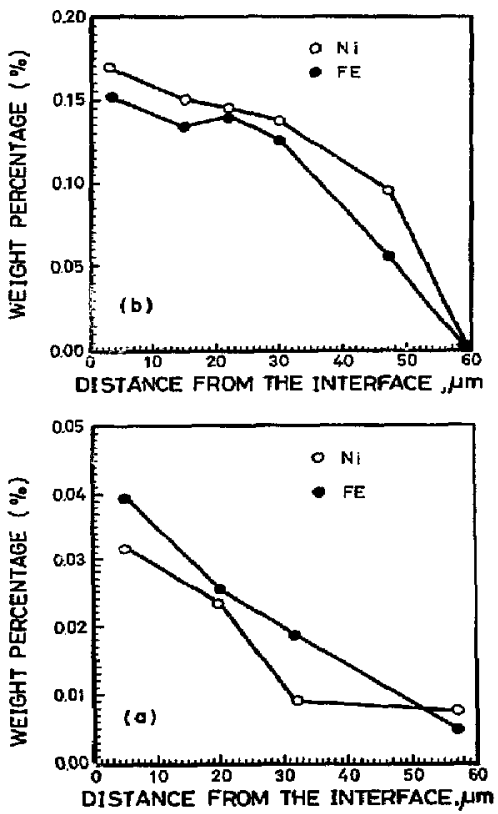

Fig. 9. Quantitative analysis of the work elements beneath the rake face: (a) $P 20$ carbide and (b) $K 20$ carbide.

EDAX, and the result is given in Fig. 11 (b). These two figures provide another evidence that tool particles do detach from cutting tool during the cutting process.

\section{Tool wear mechanism}

From the experimental results presented in the previous section, the following inferences of carbide tool wear in machining of In7 18 may be drawn.

An apparent sticking layer formed on the tool face near cutting edge indicates that bonding belween chip-tool interface had occurred. The bonding is likely originated from the driving force of very large stresses or high chemical affinity between tool and chip.

The fact of the rounding of tool particles and EPMA analyses had proved that elements of the work material had diffused into the tool, and these elements distributed around the 

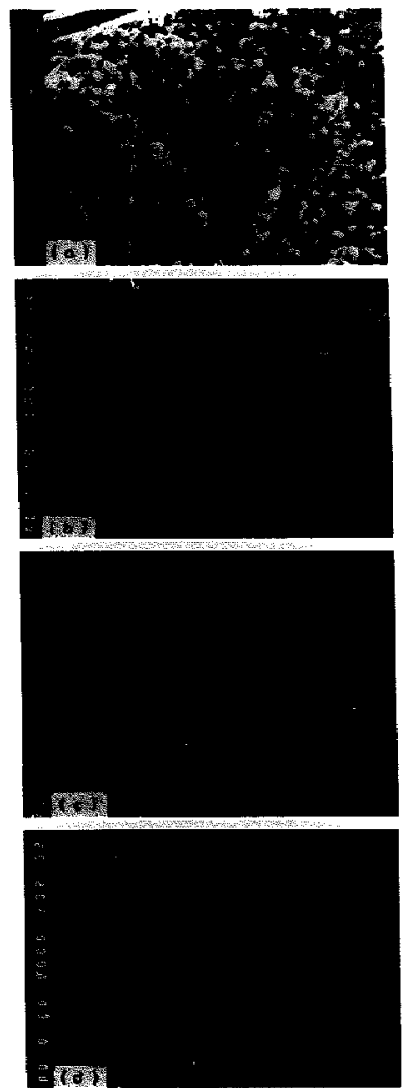

Fig. 10. (a) SEM of P20 tool's cross-section; (b) EPMA mapping af Co; (c) EPMA mapping of Ni, and (d) combination of (b) and (c).

binder Ca and the intermetallic phases between carbides and binder.

The Co-Ni and Co-Fe phase diagrams show that $\mathrm{Ni}$ and Fe can be dissolved almost completely with $\mathrm{Co}$ at elevated temperatures [13]. This fact together with about $10 \%$ solubility of carbides in $\mathrm{Ni}$ and $\mathrm{Fe}$ at elevated temperature [11] implies that the tendency for work particles to diffuse into the binder is far larger than into tool particles. Hence, the assumption that the work materials had diffused into the binder is reasonable. The thecretical computation of diffusion distance had been carried out and it is given in Appendix $B$. The diffusion distance for the diffusion along the grain boundary at high temperature $\left(>1000^{\circ} \mathrm{C}\right)$ is in the order of $10^{1}-10^{3} \mu \mathrm{m}$, whilst that for bulk diffusion is $10^{\circ}-10^{2} \mu \mathrm{m}$. Since from Figs. 7.9 it has been found that the work elements $\mathrm{Ni}$ and Fe distribute at $>10^{\prime} \mu \mathrm{m}$ below the rake face, it is concluded titat $\mathrm{Ni}$ or Fe enters into the tool by ways of grain boundary diffusion, and it will distribute around the binder Co.

The rounding of tool particles (TiC, TaC, WC) in Fig. 6 also implies that the intermetallic phases of tool particies had dissolved at the existence of $\mathrm{Ni}$ around $\mathrm{Co}$. The bonding between tool particles and $\mathrm{Co}$ would therefore be destroyed. It should be noted that the strength of Co itself would not be affected significantly by the presence of $\mathrm{Ni}$ around the grain boundary of $\mathrm{Co}$. This is because the $\mathrm{Co}-\mathrm{Ni}$ and $\mathrm{Co}-\mathrm{Fe}$ phase diagrams have shown that $\mathrm{Co}$ and $\mathrm{Ni}$ (or $\mathrm{Fe}$ ) can dissolve each other very well.

Since the bonding strength between tool particles and the binder had been destroyed, and there are high flow stresses during the cutting process, the tool particles will then be detached from tool surface. This is verified by Fig. 6. The wear resistance of the binder (Co) is very poor. Hence, when Co is exposed on the tool surface after the detachment of tool particles, the cutting tool will wear very rapidty. The solubility of titonium carbide in nickel is larger than that of tung
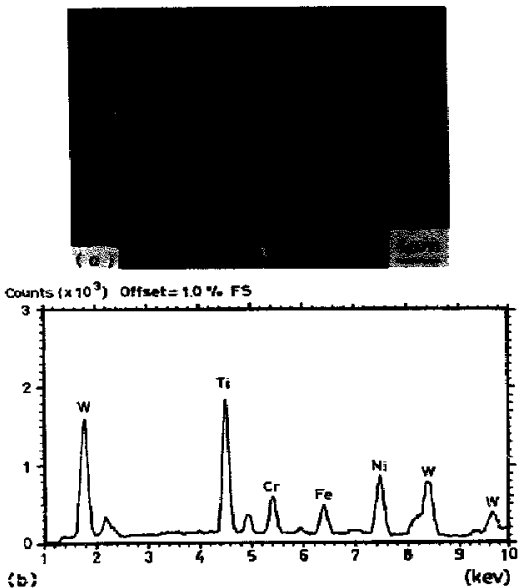

(a)

(kev)

Fig. 11. The hack of the chip: (a) phorograpti under SEM, and (b) composition analysis of complex estridtes by EDAX. 


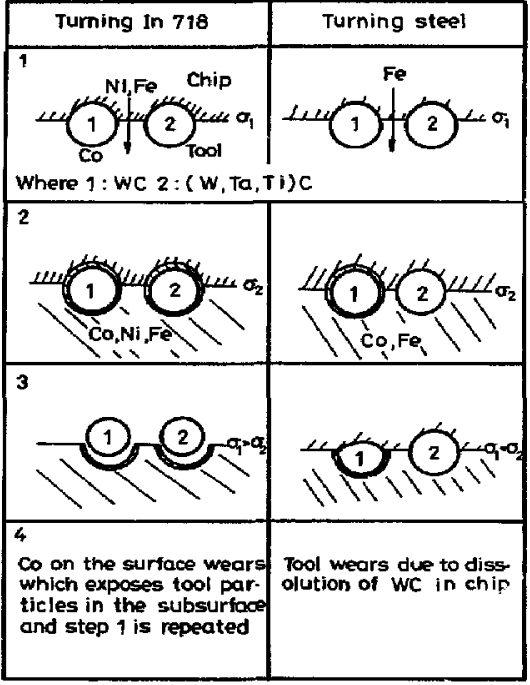

Fig. 12. Graphical illustration of carbide tool west mechanisms in turaing In 718 and steel.

sten carbide in nickel [ 11$]$. In addition, P-type carbide has a higher Co content ( $>10 \%$ ) than that of K-type's $(<6 \%)$. Hence, P-type carbide results in a far shorter tool life than $\mathbf{K}$ type's in machining Inconel 718.

Based on the discussions described above, a tool wear mechanism for the use of carbide (either K-type of P-type) in turning of Inconel 718 is postulated as follows:

Step 1 Bonding between chip-tool interface is formed due to high stresses and temperature.

Step $2 \mathrm{Ni}$ or Fe diffused into the Co grain boundaries, and the intermetallic phases between tool particles and binders by ways of grain boundary diffusion due to high temperature.

Step 3 The intermetallic phases are dissolved due to high affinity of tool particles with $\mathrm{Ni}$. This process causes destruction of the bonding between tool particles and $\mathrm{Co}$.

Step 4 When the bonding between tool particles and $C o$ is less than that between tool particles and chip, large number of tool particles are detached from the tool. This is followed by rapid wear of $\mathrm{Co}_{\mathrm{o}}$, and step one is repeated.

The proposed wear mechanism is graphically illustrated in Fig. 12. When Inconel 718 is machined by carbide tools, bonding between chip-tool interface takes place first (step 1). This is followed by diffusion of $\mathrm{Ni}$ or $\mathrm{Fe}$ into $\mathrm{Co}$ grain boundary $(\operatorname{step} 2)$. In the third step, the intermetallic phases are dissolved. In the figure, particles 1 and 2 represent $W C$ and (W,Ta,Ti)C, respectively, $\sigma_{1}$ is the bonding strength at chip-tool interface (i.e. fow stress), and $\sigma_{2}$ is the strength of Co (binder) on tool particles. When $\sigma_{1}$ is larger than $\sigma_{2}$, tool particles are detached from the cutting tool. The binder will then expose on the tool surface and wear away easily. Subsequently, the tool particles at subsurface appear on the tool surface, and the whole processes is repeated.

For comparison purpose, the use of same wear mechanism to explain carbide tool wear in machining of sitels is also illustrated in the same figure. A few differences are noticed. Since the flow stress (0.1-0.5 GPa [13]) is not large enough (i.e. $\sigma_{1}<\sigma_{2}$ ), tool wear is mainly due to dissolution of the surface of WC particles in chip $[11,14]$ rather than detachment of WC particles from tool material. This can be confirmed when the wear surfaces obtained by Naerheim and Trent [14], and Wright and Chow [12] are examined; the surface is found to be comparatively more smooth, and there is no detachment of tool particles. The solubility of WC (Ktype carbide) in iron is $\approx 2.6 \times 10^{-3}$ at $1600^{\circ} \mathrm{K}$, while it is $\approx 6.1 \times 10^{-3}$ for TiC (P-type carbide) in iron [11]. Since for P-type carbide, the solubility of TiC in iron is very small, there is very slight possibility for intermetallic phases to dissolve in iron. Hence, the TiC particles remain almost unchanged, and tool life is long.

\section{Conclusion}

A mixed type weas mechanism for turning of Inconel 718 by cemented carbide tool is postulated. At high cutting speed (in our case it is $35 \mathrm{~m} \mathrm{~min}^{-1}$ ), the tool particles will diffuse into the binder ( $\mathrm{Co}$ ) by means of grain boundary diffusion. This mechanism weakens bonding strength between carbide tool particles and binder, ard the tool particles are detached from base material under an extremely high flow stress (1$3 \mathrm{GPa}$ ). The postulated meclsanism is confirmed by experimental results. Moreover, the mechanism is also applicable to interpret the wear of cemented carbide tool in machining of steels.

Appendix A. Equations to compute stresses and temperatures

For tho orthogonal cutting, let $v, r, b$ and $\alpha$ denote the eutting speed, undeformed chip thickness, depth of cut and the rake angle of the cutting tool. The quantities $k, K$ and $p C$ are thermal conductivity, thermal diffusivity and volume specific heat of the work material. The output variables $F_{\mathrm{p}}$ and $F_{\mathrm{q}}$ are the principle and feed forces, $\phi$ is the shear angle, $a$ is the chip-tool contact length, $r=t / t_{\mathrm{c}}$ ( $t_{\mathrm{c}}$ is the chip thickness). Then, the normal stress $S_{\mathrm{n}}$ and shear stress $S_{\mathrm{s}}$ and temperature $T$ can be computed as follows: [1] 
(i) Primary deformation zone:

$S_{\mathrm{n}}=\frac{\left(F_{\mathrm{p}} \sin \phi+F_{\mathrm{q}} \cos \phi\right) \sin \phi}{b t}$

$S_{\mathrm{s}}=\frac{\left(F_{\mathrm{p}} \cos \phi-F_{\mathrm{q}} \sin \phi\right) \sin \phi}{b t}$

$T_{s}=\frac{R_{1} \omega_{3}}{J \rho_{1} C_{1}}+T_{\mathrm{a}}$

where $\mu_{\mathrm{s}}=S_{\mathrm{s}} \gamma$, and $\gamma=\tan (\phi-\alpha)+\cot \phi, J$ is the energyheat conversion factor, $T_{0}$ is the ambient temperature, and $R_{1}=1 /\left[1+1.328 \sqrt{K_{1} \gamma /(V t)}\right]$. The quantities $k_{1}, K_{1}$, and $\rho_{1} C_{1}$ are all cvaluated at $(1 / 2)\left(T_{\mathrm{s}}+T_{\mathrm{o}}\right)$.

(ii) Secondary deformation zone:

If $F_{\mathrm{c}}=F_{\mathrm{p}} \sin \alpha+F_{\mathrm{q}} \cos \alpha, B^{\prime}=0,377 q_{2} a /\left(k_{2} \sqrt{L_{2}}\right)$, and $C^{\prime}=q_{2}\left(a \bar{A} / k_{3}\right)$, then

$S_{\mathrm{n}}=\frac{F_{\mathrm{p}} \cos \alpha-F_{\mathrm{a}} \sin \alpha}{a b}$

$S_{\mathrm{s}}=\frac{F_{\mathrm{s}}}{a b}$

$T_{\mathrm{r}}=R_{2} B^{\prime}+T_{\mathrm{s}}$

where $q_{2}=F_{c} r V / J a b, \quad L_{2}=0.25 V a r / K_{2}, \quad R_{2}=\left(C^{d}-T_{\mathrm{s}}+\right.$ $\left.T_{\mathrm{o}}\right) /\left(B^{\prime}+C^{r}\right)$, and

$\vec{A}=\frac{2}{\pi}\left[\ln \left(\frac{b}{a}\right)+\frac{2}{3}\left(\frac{a}{b}\right)+\frac{1}{2}\right]$

The quantities $k_{2}$ and $K_{2}$ are thermal properties of work material, and $k_{3}$ is the thermal conductivity of the tool material. They are all svaluated at $\boldsymbol{T}_{\mathbf{r}}$.

In actual calculation of cutting temperatures, $k_{1}$ or $k_{2}$ is taken as a function of temperature, and it is equal to $10.7+8 \times 10^{-3} \mathbf{T}\left[\mathrm{W} \mathrm{m}^{-1} \mathrm{~K}^{-1}\right]$, where $T$ is in kelvins. The density of Inconel 718 is $8.21 \mathrm{mg} \mathrm{m}^{-3}$, and $C$ is 0.104 . For tool material, $k_{3}$ is 100 for K20 carbide, and it is 50 for $\mathrm{P} 20$ carbide.

\section{Appendix B. Theoretical analysis}

The diffusion concentration denoted by $c$ at a position of coordinate $(x, y)$ under grain boundary diffusion can be written as [15]:

$c(x, y, t)=C_{\mathrm{b}} \exp \left[\frac{-y \sqrt{2}}{\left(\pi D_{\mathrm{l}}\right)^{1 / 4}\left(\delta D_{\mathrm{b}} / D_{\mathrm{l}}\right)^{1 / 2}}\right]\left[1-\operatorname{erf}\left(\frac{x}{2 \sqrt{D_{\mathrm{l}} \mathrm{r}}}\right)\right]$

where $C_{\mathrm{v}}$ is a cons $n, D_{1}$ is lattice diffusivity in $\mathrm{cm}^{2} \mathrm{~s}^{-1}, D_{\mathrm{b}}$ is grain boundary fifusivity, $\delta$ is sheet thickness where diffusion takes place $\approx 4 \AA$ ), and $t$ is time. If $R$ is gas constant, and $T$ is temperaere in keivins, then diffusivities $D_{\mathrm{b}}$ and $D_{1}$ can be expressec- 45 .
$D_{\mathrm{b}}=D_{\mathrm{ub}} \exp \left(-\frac{Q_{\mathrm{ub}}}{R T}\right)$

$D_{1}=D_{\text {oi }} \exp \left(-\frac{Q_{0}}{R T}\right)$

The parameters $D_{\mathrm{ob}}, D_{\mathrm{ol}}, Q_{\mathrm{ob}}$ and $Q_{\mathrm{ol}}$ for $\mathrm{Ni}$ and $\mathrm{Fe}$ are given in Table 4.

If $\beta$ is defined as

$\beta=\frac{D_{\mathrm{b}} \delta}{2 D_{1} \sqrt{D_{1} \delta}}$

Table 4

Numerical values of $D_{\mathrm{d}+} D_{\mathrm{D} t} . Q_{\mathrm{os}}$ and $Q_{\circ}$ for $\mathrm{Ni}$ and $\mathrm{Fe}$

\begin{tabular}{lllll}
\hline Element & $\begin{array}{l}D_{c 1} \\
\left(\mathrm{~cm}^{2} \mathrm{~s}^{-1}\right)\end{array}$ & $\begin{array}{l}D_{\infty} \\
\left(\mathrm{cm}^{2} \mathrm{~s}^{-1}\right)\end{array}$ & $\begin{array}{l}Q_{\text {ol }} \\
\left(\mathrm{keal} \mathrm{mol}^{-1}\right)\end{array}$ & $\begin{array}{l}Q_{\infty b} \\
\left(\mathrm{keal} \mathrm{mol}^{-1}\right)\end{array}$ \\
\hline $\mathrm{Ni}$ & 1.9 & $\mathbf{0 . 0 3 1}$ & 68.0 & 25.6 \\
$\mathrm{Fe}$ & 18 & $\mathbf{8 . 8}$ & 64.0 & 40.0 \\
\hline
\end{tabular}
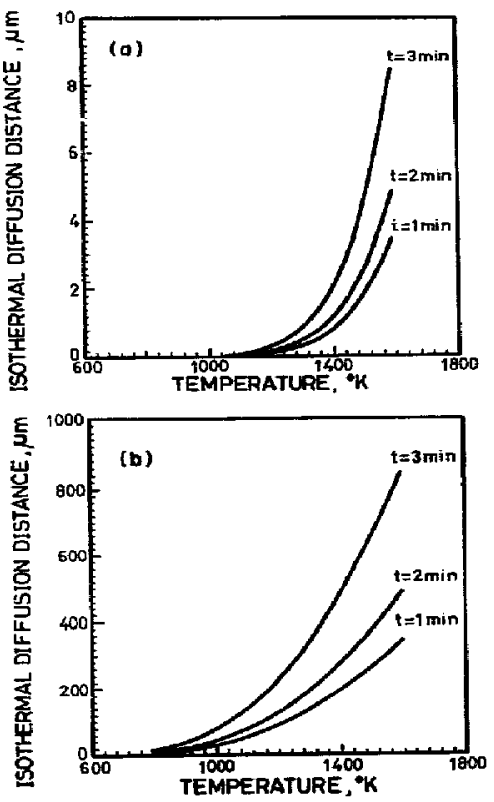

Fig. i.: Yiveoretical isothermel diffusiog distance of $\mathrm{Ni}$ (a) bulk diffusion and (b) grain boundary diffusion. 

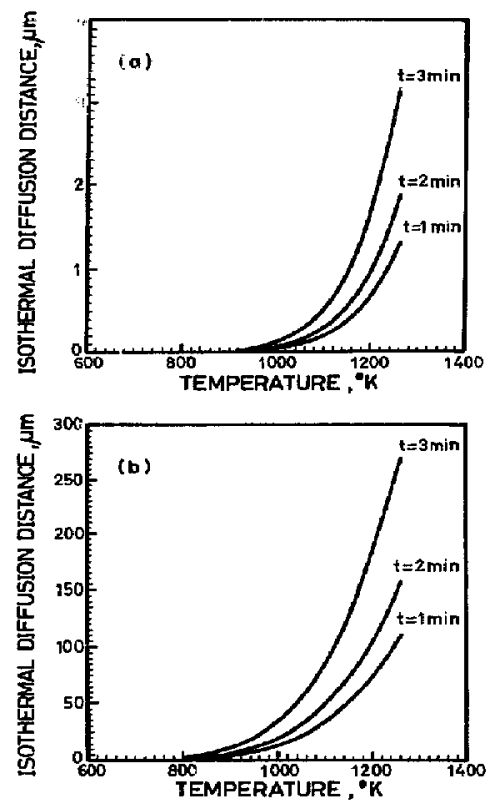

Fig. 14. Theoretical isothermal diffusion distance of Fe: (a) bulk diffusion and (b) grain boundary diffusion.

then, it had been proved that grain boundary diffusion is the main way for atomic diffusion when $\beta>1.0$ [16]. By substituting Eq. B2 and Eq. B3 into Eq. B4, it can be found that grain boundary diffusion for $\mathrm{Ni}$ and $\mathrm{Fe}$ becomes important at temperatures of $1250^{\circ} \mathrm{C}$ and $980^{\circ} \mathrm{C}$ respectively. The maximum diffusion distance under grain boundary diffusion for $\mathrm{Ni}$ or $\mathrm{Fe}$ atoms can be estimated by applying isothermal diffusion theory. The theoretical diffusion distance can be expressed as

$X=\sqrt{2 \tilde{D} t}$ where in the above equation, $\boldsymbol{X}$ is the diffusion distance in $\mu \mathrm{m}, \bar{D}$ is the diffusivity in $\mu \mathrm{m}^{2} \mathrm{~s}^{-1}$, and $\mathrm{t}$ is the diffusion time (in our case, it is the cutting time in seconds). Substituting $D_{\mathrm{b}}$ and $D_{1}$ for $\mathrm{Ni}$ and $\mathrm{Fe}$ into $\mathrm{Eg}$. BS, the theoretical diffusion distances for $\mathrm{Ni}$ and $\mathrm{Fe}$ at various cutting times can be drawn, and they are given in Fig. 13 and Fig. 14. From these figures, it can be seen that the diffusion distance by means of grain boundary diffusion at high temperatures. $\left(>1000^{\circ} \mathrm{C}\right.$ ) is around $10^{1}-10^{3} \mu \mathrm{m}$, while for bulk diffusion it is around $10^{0}-10^{1} \mu \mathrm{m}$. There is significant difference in terms of the order of the diffusion distance for two kinds of diffusions.

\section{References}

[1] M.C. Shaw, Metal Cutring Principles, Clarendon Press, Oxford, 1984.

[2] N. Zatin and J. Christopher. Machining characteristies of difficuit to machine marerial, in V.A. Tipnis (ed.). Infuence of Metallurgy on Machinability, ASM, 1975, pp. 296-307.

[3] H.R. Conaway, Machining the high-nickel alloys, in V.A. Tipnis (ed.) Influence of Metallurgy on Machinability. ASM, 1975, pp. 247-256.

[4] R. Komanduri and T.A. Schroeder, On shear instability in machining a nickel-iron base superalloy, Trans. ASME, J. Eng. Ind, 108 (1986) 90-100.

[5] E.C. Orth and S. Ebenhoch, Machining work-hardening metals, Carbide Tool J. I5 (1983) 3-7.

[6] I. Han Computetized machinability study for Incone]-J18, in V.A Tipnis (ed ), Inftuence of Metallurgy an Machinability, ASM, 1975, pp. $324-346$.

[7] N. Narutaki, Y. Yamane, K. Hayashi and T. Kitagawa, High speed machining of Inconel 718 with ceramic tools, Ann. CIRP, 42 (1) (1993) 103-106.

[8] J. Vigneau and P. Bordel, Influence of the microstructure of the composite ceramic tools on their performance. Anm. CIRP. 36 (I) (1987) $13-16$.

[9] A.E. Focke. F.E. Westermann, J. Kemphaus, W.T. Shin and M. Hoch, Wear of superhard materials when cutting superalloys, in Wear of Materials, ASME, 1977, pp. 228-237.

[10] M.T. Tan, Groove wear of tools in NC turning of pure nickel, Ann. CIRP. 35 (1) (1986) 71-74.

[11] B.M. Kramer and N.P. Suh, Tool wear by solution: a quantitative understanding, Trans. ASME, J. Eng. Jnd., J02 (1980) 303-309.

[12] P.K. Wright and J.C. Chow, Deformation characleristics of nickel alloys during machining. Trans, ASME, J. Eng. for Indusiry. 104 (1982) 85-93.

[13] 5.L. Murray, H.B. Lawrence and B. Hugh, Binary Alloy Phare Diagrums, ASM, 1986.

[14] Y. Naerheim and E.M. Thent, Diffusion wear of cemented carbide tools when culting sieel at high speeds, Metals Tech., (1977) 548-556.

[15] J.C. Fisher, Colculation of diffusion penetration curves for surface and grain boundary diffusion. J. Appl. Phys, 22 (1) (1951) $74-77$.

[16] P.G. Shewmon, Diffusion in Solids, McGraw-Hill, 1972. 